\title{
Toolbox of activities to support students in a physics gateway course
}

\author{
Calvin S. Kalman ${ }^{1,2, *, \dagger}$ and Shelley Rohar $^{2, \dagger}$ \\ ${ }^{1}$ Department of Physics and Centre for Study of Learning and Performance, Concordia University, Montreal, Quebec, Canada H4B 1R6 \\ ${ }^{2}$ Department of Educational and Counseling Psychology, McGill University, Montreal, Quebec, Canada H3A 2T5
}

(Received 14 April 2010; published 31 August 2010)

\begin{abstract}
This paper presents a set of activities, which scaffolds students to succeed in the standard Physics gateway course. The set of instructional activities that were designed included four distinct components: reflective writing, collaborative groups, critiques, and an essay question on the examination. Each activity was designed to lead into and connect with the other activities, with the intention that students would establish links between different parts of the course. Implementation was studied at three postsecondary institutions. The results demonstrate that the combination of instructional activities were successful in scaffolding the students and getting them to view the course in a holistic manner.
\end{abstract}

DOI: 10.1103/PhysRevSTPER.6.020111

PACS number(s): 01.40.Di, 01.40.Fk, 01.40.gb

\section{INTRODUCTION}

This paper is one of a series of quantitative and qualitative studies performed over the last ten years that consider an array of activities developed to assist students in succeeding in the standard Physics gateway course. In addition to a brief review of previous quantitative and qualitative studies at a single large urban university, this paper reports on new qualitative studies at two other post-secondary institutions that serve to extend the program of research.

For a student taking a science gateway course, the language and epistemology of science are akin to a foreign culture: "All of science including discovery takes place in a social and cultural milieu" [1]. Indeed, research shows that most students have loosely organized course concepts in contrast to the web of interconnections perceived by their instructors [2-5]. In particular, Hammer shows how some students view physics as weakly connected pieces of information to be separately learned, whereas others view physics as a coherent web of ideas to be tied together. Support for this view is found in a study by Huffman and Heller [6] of 750 university students in a calculus-based introductory physics course that shows that most students' personal (alternative) scientific conceptions "are best characterized as loosely organized, ill-defined bits and pieces of knowledge that are dependent upon the specific circumstances in question" (p. 141).

These results have bearings on epistemological theories proposed in the 1980's and 1990's. At that time it was assumed that students enter introductory physics courses with well-formed, robust concepts and attitudes that differ from the Newtonian framework taught in these courses. It is intrinsic to the theory of Posner, Strike, Hewson, and Gertzog [7] that students enter gateway courses with a coherent set of ideas about science. Thus Posner, Strike, Hewson, and Gertzog [7] state that one of the two questions that their theory proposes to answer is "Under what conditions does one central concept come to be replaced by another?" It was cer-

\footnotetext{
*calvin.kalman@concordia.ca

†FA: (514)848-2828.
}

tainly a given among everyone involved in science educational research in the late 1980's and early 1990's that students did have a coherent set of ideas about science. Thus for example in the in-depth analyses of student attitudes in Physics undertaken by Halloun and Hestenes [8], McDermott [9], McDermott, Rosenquist, van Zee [10], Gunstone, Robin Gray, and Searle [11] and Bowden, Dall'alba, Martin, Laurillard, Marton, Masters, Ramsden, Stephanou, and Walsh [12] it is shown that students enter introductory courses with viewpoints differing significantly from paradigms that will be taught them.

It is also intrinsic to some other types of theories that emerged in the 1990s that students have a coherent set of ideas about science. Vosniadou [13] for example argues that concepts are entrenched and constrained within a larger theoretical structure. She postulates that students' viewpoints about nature are contained in framework theories in addition to various specific theories. The learner's framework theory is a function of ontological and epistemological presuppositions and is not available to her conscious awareness. However, this framework theory constrains the process of observing the physical world that is the basis of the students' specific theories. These specific theories are consciously accessible and consist of a set of interrelated propositions that describe the observed behavior of physical objects. Vosniadou [13] identifies two kinds of conceptual change, enrichment, and revision which are basically identical to Piaget's notion of assimilation and accommodation. Enrichment is described as the simple addition of new information to existing knowledge, and achieved through the process of accretion. Revision is taken to be conceptual change and viewed as a substantial change that occurs when new information is inconsistent with specific theories or framework theories. Vosniadou [13] suggests that students' difficulties in making a conceptual change are not only because framework theories are coherent systems of explanations that are based on everyday experiences and grounded in years of confirmation, but additionally, because these are ontologically and epistemologically based. Thus a shift in any of a student's beliefs will create a shift in the entire system of the framework theory and all the other knowledge built upon it.

It has been long established that traditional methods based primarily upon lectures have a negative effect on student 
interest and motivation to persist with science and engineering as a career [14]. Watters and Watters [15] point out that "information delivered in a mass lecture format accompanied by multiple choice examinations establishes a context that fosters learning by memorization."(p.20).

With the above concerns in mind, we designed a set of activities for an introductory ("gateway") physics course, the goal of which was to scaffold students to develop a scientific mindset and to take a holistic view of the elements of the course. In doing so, we were particularly concerned with taking into account the knowledge that many students on entering the course have personal (alternative) scientific conceptions that are loosely organized.

\section{COURSE OVERVIEW AND RATIONALE}

Feyerabend's [16] principle of counterinduction states that evaluation of a theoretical framework does not occur until there is an alternative. A scientist who is interested in maximal empirical content, and who wants to understand as many aspects of his theory as possible, will adopt a pluralistic methodology, he will compare theories with other theories rather than with "experience," "data," or "facts" ..."Galileo is one of those rare thinkers who wants neither forever to retain natural interpretations nor altogether to eliminate them. Wholesale judgments of this kind are quite alien to his way of thinking. He insists on a critical discussion to decide which natural interpretations can be kept and which must be replaced. (Italics supplied by Feyerabend [16], p. 58.)

Feyerabend notes that Galileo in his early works had been a follower of Ptolemy and he argued against the motion of the Earth:

... objects which one lets fall from high places to the ground such as a stone from the top of a tower would not fall toward the foot of the tower; for during the time which the stone coming rectilinearly toward the ground spends in the air, the Earth escaping it, and moving toward the east would receive it in a part far removed from the foot of the tower in exactly the same manner in which a stone that is dropped from the mast of a rapidly moving ship will not fall toward its foot, but more toward the stern" [17].

Only later did he adopt the Copernican point of view and assume that the stone dropped from the mast would fall toward its foot. Feyerabend's conclusion is that Galileo only arrives at the modern theory of inertia by a critical examination of the tower experiment in light of two alternative frameworks: that of Ptolemy and that of Copernicus.

In this vein, efforts to produce conceptual change among students taking high school science courses and university gateway courses have typically been premised upon the idea of changing students' theoretical frameworks A major stumbling block in such an approach is that the students do not conceive of the subject in terms of a coherent theoretical framework [2-5]. The student's paradigm in the Kuhnian sense [18], is that the subject consists of solving problems using a tool kit of assorted practices. Hence, they do not conceive of the course content in terms of a theoretical framework. Paul Hewitt, the author of several college and high school textbooks including the best selling "Conceptual
Physics" (Addison Wesley, 2009) has noted: "The professor classifies the problems in terms of physics concepts, while the students classify them by situations" [19]. Thus a simple conceptual change from personal scientific concepts to scientifically accepted concepts is unlikely to enable students in science gateway courses to approach the textbook and the lectures in a scientific manner

The course [introductory calculus-based mechanics] was designed to present material that contrasted the GalileanNewtonian framework with the framework developed by Aristotle. The intention is to have students first view the frameworks almost in a theatrical sense, as though they are viewing a drama involving a conflict of actors; Aristotle, Galileo, Newton and other key "actors" in the history of science. As students progress through the various course components, they gradually become aware that the frameworks relate concepts from different parts of the course, and they learn to evaluate the two alternative frameworks. In other words, they develop a "scientific mindset," changing their outlook on the course material from the viewpoint that it consists of a tool kit of assorted practices, classified according to problem type, to the viewpoint that it comprises a connected structure of concepts.

In the design of the course, provision of alternatives to promote such an evaluation were not only implemented on the micro scale, but also on the macro scale of the entire course. The research proceeded from the assumption that students view science as weakly connected pieces of information to be separately learned in contrast to the web of interconnections perceived by their instructors. Consequently, students cannot evaluate their entire framework until they understand that the chapters in the textbook and the presentations in class are all based on a single unified framework developed initially by Newton. The course design attempted to take into account all of the above-mentioned concerns

\section{DESIGN OF THE COURSE}

Students' exploration of the concepts in the course occurs through a set of different activities (see Fig. 1), and includes four components: reflective writing, collaborative groups, critiques, and an essay question on the final examination. Each of the four course components will be briefly sketched. Following this, an overview of the research that has been carried out on the course will be presented. As will be shown, this research employed both quantitative and qualitative methods and proceeded over several years involving three different postsecondary institutions.

\section{A. Component 1: Reflective writing}

The process of helping students form an integrated view begins with reflective writing. With this activity, the students metacognitively explore the material in the textbook before it is encountered in the classroom. Reflective writing sets up uncertainty in students' views of the subject: students expect answers, but they cannot fully understand the material so they do not yet have answers. Additionally, there is disequilibrium between the students' perceptions and the foreign 


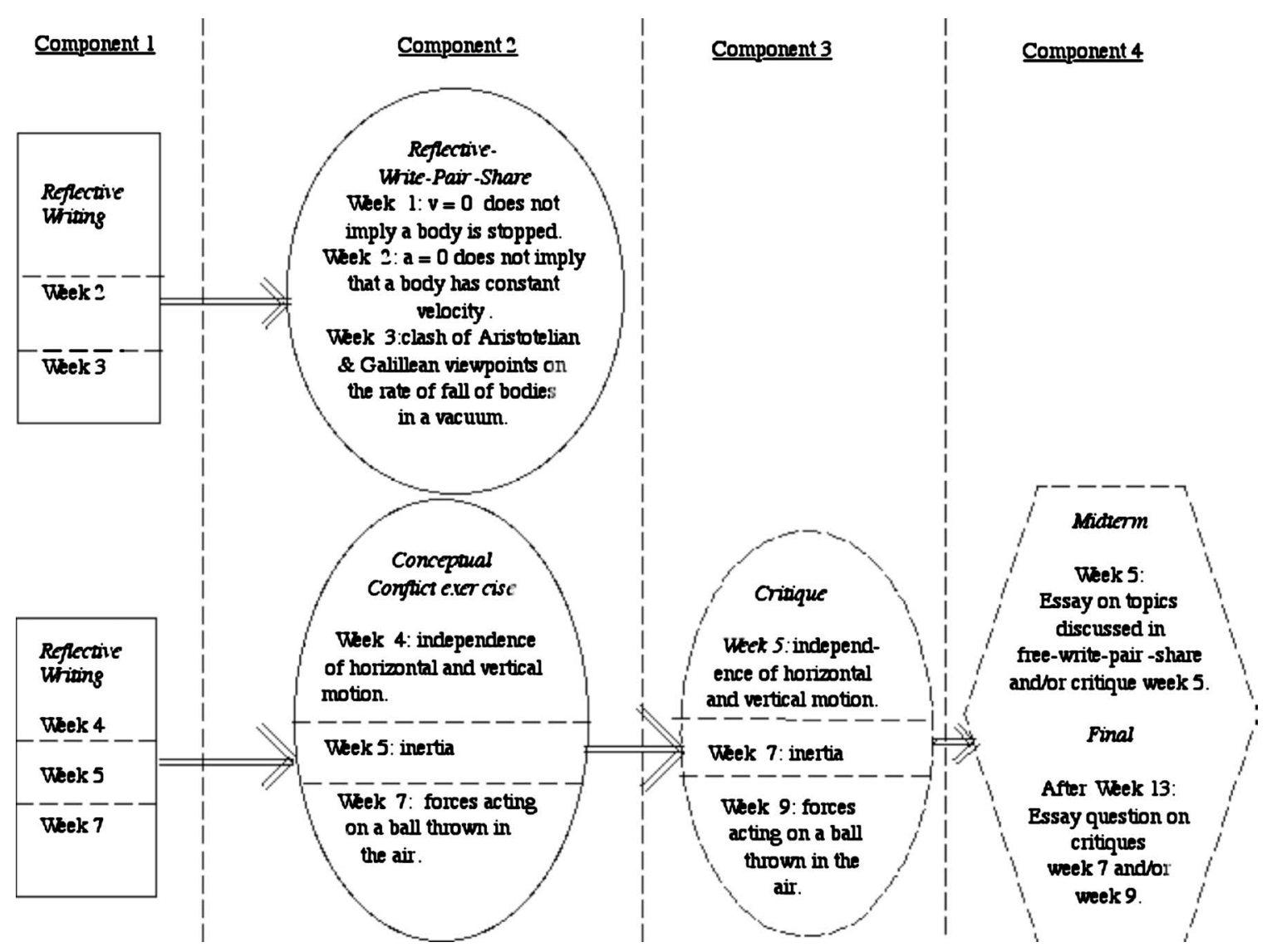

FIG. 1. The set of different activities including four components utilized in the course.

("scientific") language of the textbook. As shown in Fig. 1, this first component was employed by the students in weeks two through thirteen. The five particular weeks shown in the diagram are meant to show the flow from this activity to the others.

The instructions for performing reflective writing are found below. [Samples of students' reflective writing are found later on in this paper.]

Reflection: Suggested length five pages, but there is no page limit. In advance of the class read the assigned material for the next week's class. Read each section very carefully trying to zero in on what you do not understand, and all points that you would like to be clarified during the class. Next, write the section description on a sheet of paper as a heading, with the time and date beside it. Underneath the heading free write about what you have read. When you have finished free writing on all the sections reread your jottings and produce a 1 page preview of important ideas to be discussed in class that week. The free writing will not be marked, but unless you hand in an adequate amount of free writing with your preview sheet, the preview sheet will not be marked.

Keys, Hand Prain, and Collins [20] state, "encouraging students to write is to encourage them to negotiate meaning and construct knowledge" (p.1066). Prior evidence has indicated that writing promotes deep conceptual understanding $[21,22]$. As such, the hope was that by having students perform this activity they would forge conceptual links between the new concepts to be studied that week with concepts studied earlier in the course.

\section{B. Component 2: Collaborative-group exercises}

The mechanics course begins with a description of nature in terms of displacement, instantaneous velocity, and acceleration. The first two reflective-write-pair-share $[23,24]$ activities have students explore these concepts. Students are to see that $v=0$ at one particular time does not imply that the body is stopped and $a=0$ at one particular time does not imply that a body has constant velocity. The third reflectivewrite-pair-share intervention contrasts Galileo's views with those of Aristotle about bodies falling near the Earth's surface in a vacuum. It begins with the professor taking some keys out of his pocket and picking up a piece of paper. The two of them are dropped. The paper is then balled and again dropped along with the keys. The following transparency is then displayed,

Consider the paper and the keys in both experiments.

(a) What is involved in the motion in each case?

(b) Why do the keys and paper react differently in the first experiment?

(c) What conclusions do you draw from the second experiment?

It is pointed out that Aristotle is against idealizations; since a vacuum does not exist, the speed of a body in a vacuum should not be considered. Students are then introduced to the viewpoint of Galileo, that it is useful to consider idealizations of phenomenon occurring in the real world. Galileo's original point of view, enunciated while he was at Pisa, is introduced: he took the ratio of the terminal veloci- 
ties of objects and took the limit of where the density of the medium goes to zero. This would imply that bodies of different mass would fall at different rates in a vacuum. Students then view an experiment from "The Video Encyclopedia of Physics Demonstrations" [25] in order to illustrate Galileo's ultimate idealization; that all bodies fall at the same rate in a vacuum. It is pointed out to the students that if even an expert such as Galileo could err initially and needed to carefully examine the framework of his belief system, then it is certainly incumbent on the students to carefully examine their own ideas.

Through the conceptual-conflict collaborative-group exercise, students are introduced to the idea that there can be more than one equally logical way of looking at a phenomenon. Students will cling to their personal concepts if problems with their personal scientific conceptions do not occur. This is because these beliefs make sense in explaining observations they have made about the physical world, and having taken the effort to construct their private understanding, students will not easily relinquish their original viewpoints. Halloun and Hestenes [26] employ the analogy of a balloon to illustrate this idea. The student's assimilation of the replacement concept pushes in the balloon somewhat, leaving the student's personal concept fundamentally intact. Sufficient pressure must be applied to actually break the balloon. Hewson and Hewson [27] refer to this process as a conceptual conflict. For learning to take place, the student must compare the two conceptions and find them to be in conflict. Moreover, it is important that in the subsequent examination of the two concepts that the student not compartmentalize his or her knowledge. Roth and Lucas [28] point out that discourse analysis indicates that "peoples attitudes-or beliefrelated talk-depends a great deal on the context, and is highly variable within individuals, so that a person often expresses contradictory beliefs (sometimes within a matter of minutes)" (p. 147). Students must see that they are being presented with two different concepts and subject the two concepts to critical analysis. This is the only way that students will not simply assimilate the replacement concept by compartmentalization of their knowledge (The balloon is pushed in to make room for the replacement concept but the personal scientific concept is not discarded). The first conceptual-conflict collaborative-group exercise focuses on the independence of horizontal and vertical motion (and thus the utility of using vectors in Physics). Students are asked to compare the motion of a dropped object with an object thrown horizontally. It is noted that up to this point in the course there has been no information provided nor experiment conducted that can be used to predict the outcome of this experiment. At the end of the collaborative-group exercise, students view two experiments from "The Video Encyclopedia of Physics Demonstrations" [25]; simultaneous motion of a dropped ball and a thrown ball from the same initial height and the "monkey gun" experiment. The second collaborative-group exercise is an examination of a sandbag dropped from a hot air balloon rising at constant speed. The instructions to the class were as follows:
(1) Consider a balloon traveling upwards at $10 \mathrm{~m} / \mathrm{s}$. A passenger drops a sandbag over the side of the balloon. Your group has $10 \mathrm{~min}$ to produce a transparency describing the motion of the sandbag. (Use diagrams and words.)

(2) Two groups will report on their findings.

During the exercise students realize that various students in the class hold different viewpoints.

Once again it is emphasized that no information or experiment done to date can predict the outcome of this experiment. The comment is made that we can logically construct many possible outcomes to the experiment, but we must do the experiment to test which outcome is in accord with nature. As in the previous exercises, the discussion concludes with experiments shown from the "The Video Encyclopedia of Physics Demonstrations." The professor then describes how Galileo makes use of ideal situations to theorize about, and eventually derive, the law of inertia [29]. The professor explains that Galileo felt that this law is necessary to understand the Copernican perspective.

The final collaborative group and critique exercise continues the discussion of Galileo's revolutionary idea of inertia. Students are asked to examine the forces acting on a thrown baseball just after it leaves your hand and when it reaches the top of its motion. This brings out in the open a variety of students' personal scientific conceptions including "force being dependent on velocity" and the "force of the hand" balancing the force. In summing up, the professor emphasizes the concept of equilibrium and the role of inertia in keeping the ball moving. An inducement for this exploration is that there is an essay question based upon concepts discussed in the course on a sample midterm and students are notified that their midterm will be very similar to the sample midterm.

\section{Component 3: The critique writing activity}

We can safely begin with the hypothesis that many students are still playing the "what does the teacher want" game. Let us keep in mind as Sternberg [30] has pointed out that, "In most discourse communities, which are imbued with social traditions, great emphasis is given to such factors as deference to authority, unreflective intuition, social dexterity and timely action" (quoted in Nelson, 1994 [31], p. 47). Altogether as Nelson [31] points out:

Students are so resistant to uncertainty that they may suspect a teacher's competence if they are shown two ways of working a problem. When students see that there is no guaranteed right answer in an area, their typical response is that all opinions in the area are equally valid...(p. 52).

We must adjudicate various combinations in different contexts. Thinking becomes more complex, we come to see knowledge as constructed rather than discovered. For collaborative learning to be most effective, it is not sufficient simply to have students work together. "Left alone, they often simply create a collage of opinions" [31],

Nelson suggests that there are three ways of providing students with an intellectual scaffolding that will encourage 
them to critically examine the alternatives: "as models or frameworks that allow students to think about their thinking; as alternative possibilities within disciplinary discourse; or as an introduction to uncertainty, with alternatives to be compared and criteria for comparing them."

The in-class collaborative-group exercises of the second component were designed to produce the conceptual ecology for students to question their alternative personal scientific conceptions. The critique activity is a writing exercise in which students examined the alternatives produced in the collaborative-group exercise. It is basically an argumentative essay in which students have to put forward as many possible arguments in favor of all the conceptual viewpoints raised in class and then point out which viewpoint is correct from an experimental point of view. The critiques are designed to encourage the students to undergo a "critical discussion to decide which natural interpretations can be kept and which must be replaced" [17].

The critique corresponding to the second collaborativegroup exercise described in the previous section is as follows:
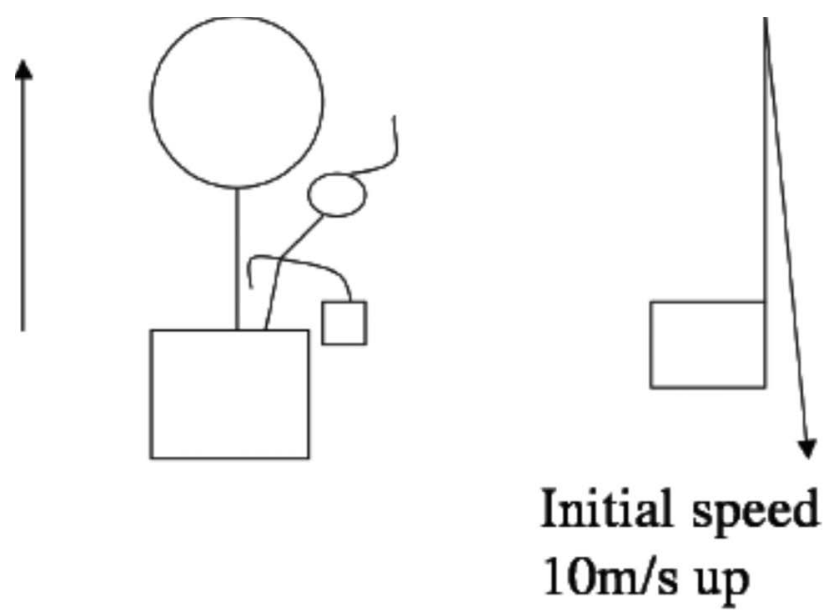

\section{Initial speed $0 \mathrm{~m} / \mathrm{s}$}

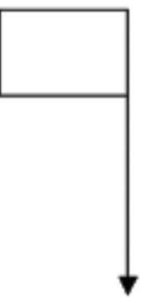

\section{At the left we see a sandbag being dropped from a balloon . (Give as many reasons as possible for each viewpoint.)}

\section{Critique\#2-Suggested length 2 pages, but there is no page limit.}

\section{Component 4: Essay question on the examination}

The fourth component comprised the midterm and final examinations. One of the questions on both the midterm and on the final exam consisted of an essay type examination of one of the concepts covered by the critiques. Students were aware that essay questions on the examinations were based upon the critiques. The midterm was held one week after the relevant conceptual-conflict exercise in class. Students did not know what to expect in terms of formatting an essay question until they had completed the midterm and received in-class feedback. Below are two typical essay questions from the final examination and midterm, respectively:

(1) Two cars are traveling South on a three lane highway at $100 \mathrm{~km} / \mathrm{h}$, one on the innermost lane and one on the outermost lane. One passenger in the rear of each car facing each other opens their respective windows and one throws a baseball straight toward the other. Ignoring air resistance, explain and justify the motion of the baseball. Discuss all forces acting on the baseball throughout the motion.

(2) Consider the motion of a rock thrown horizontally at high speed. Discuss the views of Aristotle and Galileo and the actual motion as shown by experiment.

Below is part of the answer to the above question dealing with the views of Galileo provided by one of the women in the class. The entire answer, which included the views of Aristotle completely covered all the points about these views in a humorous way and received a perfect mark for the question. 
CALVIN S. KALMAN AND SHELLEY ROHAR

PHYS. REV. ST PHYS. EDUC. RES. 6, 020111 (2010)

- all objects, despite their Is pe, wald

Fall at the same rate, due to gravity.

Now, as to tic motion of a

rock thrown horizontally, one would assume

the the acceleration would be somehow

different. If Galileo threw a rock

at his wife, who was a few feet

anvil from the Tower of Pisa, at rand at

the same time dropped a rock onto his

doggy standing directly beneath him us der the

-over, ore might think that the dos

would get hit first.

Not so! the motion of a projectile

(a) be divided into horizontal and vertical of acceleration

components ax ad ag. While He store

020111-6 
TOOLBOX OF ACTIVITIES TO SUPPORT STUDENTS IN...

PHYS. REV. ST PHYS. EDUC. RES. 6, 020111 (2010)

is flying towards bis wite, it expericices downuxel acceleration due to gravity just the salic as a freely falling stone.... but no horizontal acceleration, if we neglect air resistant.. So, the dog and the wife get nailed at the same time.

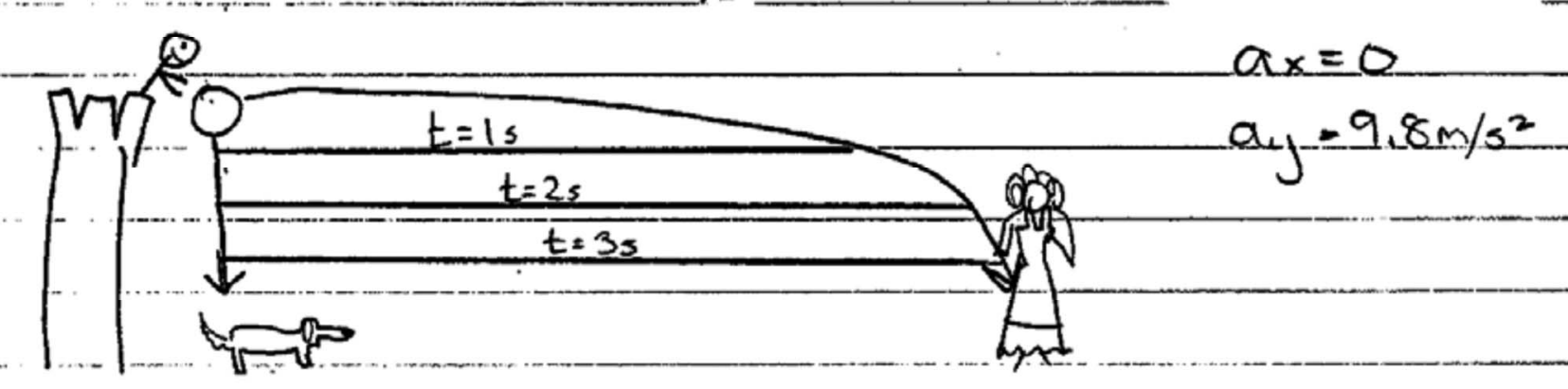

Ore con also separate the velocity components into $V_{x}$ and $V_{y}$. $V_{x}$ remains constant because it expert es no acceleration, but by will change according to downward. acceleration $\wedge$ So, $v_{x}=v_{x o}=$ constant.

$$
v_{y}=v_{y}=-g \cdot t
$$

020111-7 
TABLE I. Studies comprising program of research

\begin{tabular}{|c|c|c|c|}
\hline & Setting/population & Methods & Purpose \\
\hline $\begin{array}{l}\text { Study } 1 \text { (1999) } \\
\text { Kalman, Morris, } \\
\text { Cotton \& Gordon }\end{array}$ & $\begin{array}{l}\text { Concordia University } \\
-2 \text { groups of students in } \\
\text { two successive years } \\
\text { (Fall } 1995 \text { \& Fall 1996) }\end{array}$ & -Quantitative & $\begin{array}{l}\text { Explore the collaborative-group } \\
\text { exercise as a stand-alone activity. }\end{array}$ \\
\hline Study 2 (2004) & Concordia University & -Quantitative & Modifications were made \\
\hline Kalman, Rohar \& Wells & $\begin{array}{l}\text {-2 later groups of students } \\
\text { in two successive years } \\
\text { (Winter } 1998 \text { \& Winter 1999) }\end{array}$ & $\begin{array}{l}\text {-Students taught by } \\
\text { a different instructor } \\
\text { than in Study 1 } \\
\text { Year 1: as in Study 1, } \\
\text { collaborative group utilized } \\
\text { without follow-up of } \\
\text { critique exercise } \\
\text { Year 2, Collaborative-group } \\
\text { exercise followed up by } \\
\text { critique exercise }\end{array}$ & $\begin{array}{l}\text { to the interventions explored } \\
\text { in Study 1: Conceptual } \\
\text { conflict model } \\
\text { (using collaborative } \\
\text { group exercises) } \\
\text { was enhanced by } \\
\text { the introduction } \\
\text { of the writing-to-learn } \\
\text { exercise ("critique") }\end{array}$ \\
\hline Study 3 (2008) & Concordia University & -Qualitative & Analyze the reflective \\
\hline $\begin{array}{l}\text { Kalman, Aulls, } \\
\text { Rohar, \& Godley }\end{array}$ & $\begin{array}{l}\text {-Sample of students } \\
\text { from Study 2, year } 2 \text { (Winter 1999) }\end{array}$ & & writing activity) \\
\hline
\end{tabular}

The final examination occurred up to $21 / 2$ months after the relevant conceptual-conflict exercise in class All questions on the midterm and the final were of equal value.

\section{COURSE}

The course examined in this study was the standard gateway first course in mechanics. A course in differential calculus was a corequisite and techniques from calculus were utilized in the course. The majority of the students had completed Physics in high school. This program of research utilized several classes from Concordia University and two CEGEPs (Junior Colleges); Champlain College and Marianopolis College, all in the Montreal area. Concordia University is one of the largest urban universities in Canada. It is a comprehensive university with 44000 students enrolled in credit and noncredit courses in faculties of Arts and Science, Commerce, Engineering, and Fine Arts. The CEGEP system, unique to Quebec, Canada, features a network of compulsory junior colleges offering two-year academic programs. Students enter CEGEPs after completing grade 11 in high school, and graduating students may then enter three-year programs at Quebec universities to complete their Bachelor's degree. Quebec universities offer four-year Bachelor programs for out-of-province student. Students at the CEGEPs were all enrolled in a science specialization program.

The early studies are summarized in Table I. Subsequently a class at Champlain College utilized the reflective-writing activity and a further class at Marianopolis College made use of the entire panoply of activities that were used by the students in the second year of Study 2 (2004) and Study 3 (2008). After briefly examining the quantitative analyses of Studies 1 and 2, we report the results of a qualitative analyses of the studies at Concordia University, Champlain College, and Marianoplis College.

\section{A. Study 1}

The goal of the Kalman, Morris, Cottin, and Gordon [32] study was to examine the conceptual-conflict collaborativegroup exercise as a stand-alone activity. The purpose was to reassure students that they hold views which are reasonable, but at the same time, to have them recognize that there exists another experimentally correct viewpoint. Once the differing views of nature are clearly established, the role of experiment in deciding the issue is then emphasized; that is, it is stressed that physics is an experimental science and the ultimate determination of how things actually work must be an appeal to experiment.

The purpose of this activity was to try to make it clear to the students that there are at least two ways of looking at the problem. This must be done in a nonjudgmental fashion. Compartmentalization can occur because students are not clear that there are two distinct conceptual ways of viewing a phenomenon. Having two groups with different concepts report to the class sets up a conceptual conflict. The spokespersons of each group then debate the issue between themselves, after which the rest of the students are invited to address questions to this panel of "experts." To underline that there are two concepts in conflict, the two opposing views presented by the two groups are clearly stated and the class then votes on which concept resolves the demonstration or qualitative problem. Voting is critical to the exercise because students who have compartmentalized concepts often misinterpret statements in view of their eclectic viewpoint. The professor then resolves the conflict by explaining, with the aid of experiments, how the replacement concept describes the demonstration or qualitative problem in accord with experimental findings, while the personal (alternative) scientific conception fails to do so.

In the experiment the same professor taught both sections. In section $\mathrm{A}$, concepts 2 and 3 were treated by the 
collaborative-group method and concepts 1 and 4 were treated conventionally. In section $\mathrm{B}$, the procedure was reversed-concepts 1 and 4 were treated by the collaborative-group method, and concepts 2 and 3 were treated conventionally. Standard statistical tests showed a gain for the group experiencing collaborative learning over the control group.

\section{B. Study 2: Adding the critique exercise}

Kalman, Rohar, and Wells [33] made modifications to the interventions previously explored by Kalman, Morris, Cottin, and Gordon [32]. The conceptual-conflict model (using collaborative-group exercises) was enhanced by the introduction of a writing-to-learn exercise called a critique. The critiques were designed to encourage students to engage in the kind of critical discussion that Feyerabend deems necessary in order to decide which natural interpretations can be kept and which must be replaced. For further details refer to Kalman, Rohar, and Wells [33].

\section{Evaluating the course}

The course was then examined in several ways. First, the efficacy of the enhanced model was examined by having the students take the same enhanced version of the force concept inventory (FCI) [34] as administered to the students in the previous study. Second, a group of students in the course were interviewed on three occasions during the course. The interviews were audio- and videotaped and were later transcribed verbatim. The purpose of the interviews was to explore how the students used the various elements of the model both to get a better understanding of student learning, and also to discover how to improve the model. Third, copies of all the written materials produced by students in the course were retained for later analysis. The quantitative data based upon the FCI was presented by Kalman, Rohar, and Wells [33]. It was found that the addition of the critique produced a statistically significant improvement in Winter 1999 compared with the use of collaborative groups alone in Winter 1998.

There also appears to be a strong indication that Winter 1999 students scored better on the baseline (consisting of questions that do not relate to the concepts under study). Recall that the purpose of the critiques is to enhance the development of students' critical thinking skills so that they will carefully examine the alternatives presented to them in the conceptual-conflict exercises. Such a spillover might indicate that in doing the critiques, students do actually increase their critical thinking skills and that with such an improvement students were led to reevaluate their entire conceptual framework.

\section{QUALITATIVE ANALYSIS}

Certain questions cannot be easily addressed by quantitative methods. For example, how do students actually go about doing the activity? Do they change the way that they perform the activity during the course? How do they perceive these activities in relation to their own learning? An- swers to such questions are helpful for both educators in terms of guiding future students, as well as researchers who seek a deeper understanding of the processes involved in implementing such activities. As such, we decided to pursue a qualitative analysis of the data in order to explore these issues. The qualitative analysis consists of combining data from Study 3 [35] with data from the two colleges that were analyzed recently and which is presented here.

\section{A. Sample}

The qualitative analysis focused on three sets of students, one set from each institution. Each set consisted of five students. All the students took essentially the same first course in calculus-based physics (mechanics). The first set from Concordia University and the set from Marianopolis College performed all the activities in the course design as described in this paper. The set of students at Champlain College performed only the reflective-writing activity. There were approximately 100 students taking the course at Concordia University, 30 students at Marianopolis College and roughly the same number at Champlain College. All 15 students were interviewed by the same person. For each set, over half the class volunteered to take part in the study. Five students were selected to participate in the study at each of the institutions. We purposively selected students who represented the disciplines from which the most students in the larger population are drawn. Both men and women were selected as this was representative of the larger class. The students selected had marks on the final examination that fell between the top $25 \%$ and $75 \%$ of the class.

The actual number of students from each discipline in the course, in the order given, was: $30 \%$ Science (mostly Biology), 20\% Engineering, 20\% Mathematics and Computer Sciences, and $30 \%$ other (Humanities and Commerce). Half the students were male and the other half female. At both colleges, all the students were in either the pure and applied sciences or the biological sciences concentration.

\section{B. Method}

We followed methods used in an intrinsic case study as recommended by Stake [36] and Merriam [37]. We consider this to be an intrinsic case study because the student's perspective is of primary interest within the context of the particular course design used in this study.

All student interviews devoted to reflective writing were organized by student and then collapsed over students for each temporal period of the course beginning and ending with an interview. These divisions reflected the accumulation of teaching-learning opportunities for building strategies to improve the quality of thinking about physics phenomena. Repeated readings of the three interviews for each student led to the identification of reoccurring general and specific themes that were common to all students, as well as themes that were unique to particular students. We compared the three divisions of the course to see if students constructed reoccurring categories that might reveal underlying themes regarding their views toward reflective writing and its value to their deep understanding of the physics course content. 


\section{Analytic induction}

Part of the purpose of the interviews was to determine inductively the steps students said they followed to carry out the activity. This was done by asking students to tell us what they did first when they engaged in reflective writing, what they did next, and so on, until the student had nothing more to say. The following probes were used: "you said that you do three things ... please think out loud how you would do them based on your last reflective-writing activity. Anything else? ... What else? ... Is that about it?" Differences in responses on different sections of the course for individuals suggest changes in learning. Differences in the same procedure for all, or most of the group, even more strongly suggest these changes are attributable to reflective writing. The patterns arising from the analysis will be shown along with several representative excerpts from the interviews.

\section{Credibility}

In order to promote the credibility of the study, Moschkovich and Brenner [38] suggest that the researcher needs to carry out the research in ways that answers the question, "How well do the results capture the constructs used by participants in a context and the particular dynamics of that context?" In this study prolonged engagement occurred in the sense that the complete cycle of instruction across 13 weeks was observed by one researcher who also taught the class and was aware that no unusual or atypical events occurred.

Triangulation was also used to establish credibility. The study used three sources of data: Survey responses relating to students' initial evaluations of the reflective-writing activity, evaluative remarks in relation to the reflective-writing activity that occurred during each of three interviews, and finally, students' reflective-writing products that were collected throughout the course. Moreover, the results of the analysis of reflective-writing products were compared to the results of the interview analysis to assess whether they corresponded or conflicted with each other. Finally, member checking was used by having students review a portion of the interview transcripts from each interview for accuracy and completeness.

\section{E. Results}

\section{Cognitive activity during reflective writing}

The cognitive activity while doing reflective writing as described by the students is different from simply engaging in rote recall of a text following silent reading. Comments by Concordia student, Alexei, and by Cegep students, Fiona and Evgeny, illustrate this point.

Alexei: $\quad$ You are also forced to think about the content. It's not like memorizing. You have to understand what you are reading enough to know something to write about. ... While doing reflective writing you can often pin point particular important ideas you don't understand. It causes you to have questions too. Sometimes that is painful because you expect yourself to have answers and don't. ... I do explore the answers to my questions while doing reflective writing.

Fiona: I want to try and understand what the theories are talking about, try and get a more global understanding as to what's going on, not just what the examples want us to do. Also I want to be able to apply that to the examples.

I think that most people when it comes to science its just 'let me just do the problems, I don't even have time to understand what's going on' and that's where the problem comes in because if you don't understand then you're stuck.

We're supposed to do three pages for this and I tend to go over because I like reasking questions and asking myself "well, why is this?," "why does this happen in this case, does it happen in some other case, or is it just, or is this a special case"

Evgeny: Sometimes when I'd freewrite I'd get stuck and I'd realize that I really don't understand what I'm writing about. In those cases I'd have to go back and reread the whole section asking questions. I ask questions in the sense that, "what am I doing, I don't understand."

\section{Students' conceptual understanding}

One of the purposes of reflective writing is to get students to focus on concepts. We wanted to find out if students understood this point rather than thinking that this activity was simply meant to have them read the book before coming to class.

Interviewer: In your opinion what do you think the purpose of free writing is?

Evgeny: To understand the concepts. Free writing is the main thing that helped me understand the concepts of the chapter.

Alexei: Reflective writing helps you recover the main points of sections of the chapter and put them together to get to the point of the whole chapter. I keep track of the main points section by section, you know. What's the point? Where does it take me? Why is it important?

Fiona: To not mechanically put in numbers into equations and just calculate what something is, but to understand why this is, what the numbers mean I have to understand it first and then put it in my own words.

The qualitative results also demonstrated that reflective writing helped students gain a better understanding of the material, as illustrated through the words of Diane and Evgeny, who described improvements in their understanding after having completed this activity. 
Interviewer: How well would you say you understand the material in the section of the text before you start free writing?

Diane: before, maybe like a five, a four.

Evgeny: Ten being the best, uh, seven.

Interviewer: Then after you free write, and I don't mean after going to class, just your understanding initially and then after free writing, do you feel it's changed your understanding?

Interviewer: Then after you free write, and I don't mean after going to class, just your understanding initially and then after free writing, do you feel it's changed your understanding?

Diane: It does change, it can even go up to a seven.

Evgeny: It changes for the better because sometimes after reading the section then I'd say "oh, I really understand this." While I'm writing, I realize I might not really understand some part of it. Then I focus on that point and I make sure I do understand, that's the whole point of freewriting I guess. I'd give myself a nine, probably a nine and a half.

Most of the students indicated similar improvements.

\section{Summary writing versus reflective writing}

After our experience at Concordia, we tried to elicit from the students at Marianopolis and Champlain colleges what their thoughts were on summary and reflective writing.

Interviewer: Do you see free writing as being different from summarizing?

Fiona: I think the free writing would be better because as I ask myself questions, I prove to myself that I know what I'm talking about

Evgeny: I remember the concepts, but not everything that we've covered and I find that it [free writing] helps because if I was writing a summary, I'd probably be looking in the textbook all the time and copying out the facts just like in the textbook without really thinking about them but in the reflective-writing assignments and in the free writing I actually have to think about it without looking in the textbook and putting it into my own words. For me it helps. I think that free writing really helps me understand the concepts,

Interviewer: Do you see it helping you understand it better, or grasp the material better by doing free writing?

Laurent: It helps me come up with questions, or if I read something and if there's a loophole or there's something missing, it's not clicking in my head, I find that...because usually I don't do that, but when I'm free writing I'm more aware of it. If I was summary writing I would just say it again in my own words. You're more honest in free writing, you're saying "I don't understand this" "but I do understand this but I don't see how they connect." When I do summary writing I feel like I'm just regurgitating everything I just read. I don't like that.

\section{Connecting current and prior textual material}

In a strategy such as summarizing Physics textual material without the reflective-writing component, the writer tends to write down all the points they have distilled from the textbook until the material is exhausted. Summarizing does not foster the generation of new knowledge, because it relies on established connections between content elements and readily available discourse knowledge. The process of summarizing an assigned text is not dependent on students relating prior physics knowledge to new knowledge in the textbook. On the other hand, directed free writing involves a metacognitive response on the part of the student. Students perform a critical examination of the text. By "directed," what is meant is that this is carried out as a set task, such as trying to clarify "what do I understand" and "what do I not understand." Samples of students' writing shows that during reflective writing the students appear to actively engage knowledge garnered in previous chapters and construct links with the material: that is, that students engage in a self-dialog on the issues connecting the text they read with other parts of the textbook. A sample of Alexei's free writing illustrates this point.

Alexei: Projectile motion is the kind of motion a ball makes when thrown forward. ... As we saw with vectors, we can project its horizontal and vertical velocities out to the $x$ and $y$ axis, and its magnitude (length) can be found with the aid of trigonometry.

Continuing with reflective-writing, Alexei discovers that this connection helps him to establish an important concept; "A projectile motion can be regarded as the superposition of a free falling body and a body moving with constant velocity." Much later in the course, during reflective writing, Alexei connects kinetic energy to the earlier concepts of force;

Alexei: Kinetic energy is the energy that is closely associated with the motion of a body. In effect, it has been algebraically derived from the formula to calculate the net force, thus it can be used to describe the net force without ever having to calculate the different forces acting on an object.

Nabilla also shows evidence of relating previous textual material to her assigned reading by the sixth week of the course. She writes; "The kinematic equations that we used in Chapter two are also applicable to projectile motions." She 
uses this to make sense of the concept found in her reading of chapter 4:

Nabilla:

A particle can be considered superposition of the term $\left(V_{o} t\right)$ which is the displacement of no acceleration is present. So if there were no gravitational acceleration, then the object would move horizontally and not in a vertical direction, since there's no pull from the Earth. So in this case the vertical distance which the particle falls is the same distance, as a free-falling object would fall. So we can say that a projectile motion is super position of a motion with constant velocity (where there's no gravitational acceleration) and a motion a freefalling object in the vertical direction when $a=$ constant.

\section{Student response to the course design}

All the components of the course should come together to help the students come to understand the conceptual structure of the course and develop their critical thinking abilities.

Interviewer: Would you say that the discussions within the groups made it clear that there are at least two way of looking at the problem under examination?

Diane: It just makes me think, well what if what I'm doing is wrong. You see things in a different way because physics is not exactly how you see it; it's so different from just what you see. When you let something drop and you throw it and they both fall at the same time, I would have never known that. You can't rely on what you see anymore so you really have to think on why is that actually right.

Interviewer: Did the group work help to prepare you to do the critiques?

Diane: Yeah, and once you get the critiques done, you're like "oh, I finally get it" and you have to put everything together. It's like a puzzle. With the critiques and all those reflective-writing assignments, everything, all the laws and everything they really stick in your head, and then you know why everything happens.

Diane: Yeah, and once you get the critiques done, you're like "oh, I finally get it" and you have to put everything together. It's like a puzzle. With the critiques and all those reflective-writing assignments, everything, all the laws and everything they really stick in your head, and then you know why everything happens.

Ahmad: The group work bombards you with many ideas, and then for the critique you're going in the opposite direction, you're trying to get rid of all the ideas and come to one right idea. In the second critique or third critique, I started thinking to a previous critique, so it all builds upon itself. The first critique will help explain the second, and that helps to explain the third.

Alexei: [In the final collaborative-group exercise we] had three different opinions and everybody tried to defend his or her own opinion. There was no consensus. We did succeed in identifying those critical points in the problem, why, or why not we don't agree on it so in this case, I found it very helpful. What really helped was the final explanation by the professor, how it really worked, or how that particular situation was supposed to be looked at.

Laurent: I think that free writing really helps prepare you for group work. When I was doing the exam a lot of the stuff that I really needed to know or that I needed to focus on I covered in group work. ... When you are doing group for some reason I seem to remember more of things that happened. When you're doing group work, if you have a lot of questions to ask, a lot of doubts and such, your teammates will explain it to you in a way that you just for some reason understand.

Interviewer: Was the process of doing the critique helpful in understanding other concepts?

Diane: Yeah, because since you develop that way of thinking, and seeing it another way and you know, you're going to use that way of thinking on other problems. In that way you do develop another way of thinking and seeing things. When you come to the critique you use all those ways to think why is that happening, why is that right and why is that wrong.

Laurent: I was able to apply those concepts to other concepts because I understood them better.

Additionally it is desirable that the set of activities (Fig. 1) serves a purpose beyond the goals previously described. As "Joe" Redish [39] writes "if we want to adopt the view that we want to teach as many as possible of our students then we must adopt a mix of approaches and be prepared that some of them will not work for some students."

\section{DISCUSSION}

The purpose of this program of research was to design a set of instructional activities for an introductory physics course with two general goals in mind: first, it was anticipated that these activities would help scaffold student's thinking such that they would form an integrated or holistic view of the different elements of the course, and ultimately, move toward a greater epistemological coherence in their 
thinking about the nature of science in general. Second, it was expected these activities would also serve to increase students' awareness that there can be multiple ways of viewing phenomenon and that the determining factor in deciding which conceptualization is correct can only be arrived at via experiment, not logic.

The set of instructional activities that were designed included four distinct components: reflective writing, collaborative groups, critiques, and an essay question on the examination. Each activity was designed to lead into and connect with the other activities, with the intention that students would establish links between different parts of the course and subsequently change their epistemologies. The results demonstrate that the combination of instructional activities were successful in achieving these two primary goals.

First, as can be seen through the interview data, it appears that the instructional activities did indeed facilitate a greater holistic approach by students toward the different elements of the course. Analysis of the interview data reveals that through the reflective-writing activity students actively sought connections between different parts of the textbook. Moreover, their changing of epistemologies is clearly evidenced in the interview data. Laurent's comments provide a prime example; he points out that other science courses are formula driven and the aim is to use them in a given set of situations but that in physics you can't always do that, "You have to know why you're using the equations." In general, students point out that it is the reflective writing that helps them understand how to function in the course. It is the form of the reflective-writing assignment that promotes metacognitive examination of the material in the textbook that produces this result. The students are also clear in stating that simply summarizing the material could not lead to this result. Through our research it was shown that during reflective writing some students seemed to dialog with themselves. They seemed to clarify what they did and did not understand. The overall picture of the reflective-writing process in the context of studying the Physics textbook is that it was dynamic, it aided understanding, and it included careful reading of the required text before initiating reflective writing. While the process of establishing links begins with the reflectivewriting activity, the next components, the collaborative group and critique activities, help students in establishing another way of thinking.

The collaborative-group exercise was designed to produce the conceptual ecology necessary in order for students to question their "personal scientific concepts." The two activities comprising this component involved collaborative groups followed by full class discussions; it is through discussion among themselves that students come to the understanding that there exists a variety of viewpoints in the class about various physics concepts. Both quantitative and qualitative data supports the efficacy of the collaborative-group exercise in achieving this goal. Kalman, Morris, Cottin, and Gordon [32], showed gains for students experiencing collaborative learning in terms their understanding of over a control group of students receiving standard professorcentered instruction. Moreover, the interview data also reveals how the discussions within the group made it clear to the students that there were at least two ways of looking at the problem under examination. Diane's comment in reference to the collaborative-group exercise serves to illustrate this: "...nobody really sees it the same way. Then, it just makes me think, well what if what I'm doing is wrong. You see things in a different way because physics is not exactly how you see it; it's so different from just what you see. When you let something drop and you throw it and they both fall at the same time, I would have never known that. You can't rely on what you see anymore so you really have to think on why is that actually right."

The following component, the critique activity, was designed to promote a critical examination of the alternative possibilities that were put forward through the collaborativegroup exercise. Essentially, the critique is an argumentative essay in which students are encouraged to present as many possible arguments in favor of all the conceptual viewpoints raised in class and then point out which viewpoint is correct from an experimental point of view. The final component, the essay question on the exam, serves as an inducement for this exploration because students are informed that this essay question will contain the very concepts under exploration.

Although the results of the Kalman, Morris, Cottin, and Gordon [32] study using only an intervention based upon collaborative groups produced statistically significant gains for the group experiencing collaborative learning over the control group, the final post-test scores were low enough that there was room for further improvement. Moreover, there existed the possibility that there was resistance to the collaborative-group intervention because by itself it can create a collage of opinions [31].

Nelson [31] suggests that there are three ways of providing the students with an intellectual scaffolding that will get the students to critically examine the alternatives as models or frameworks that allow students to think about their thinking; as alternative possibilities within disciplinary discourse; or as an introduction to uncertainty, with alternatives to be compared and criteria for comparing them. The critique was introduced to critically examine alternative possibilities. The method is akin to Feyerabend's [16] principle of counterinduction.

Recall that the purpose of the critiques is to enhance the development of students' ability to carefully examine the alternatives (critical thinking skills) presented to them in the conceptual-conflict exercises. The spillover on the FCI might indicate that in doing the critiques, students do actually increase their critical thinking skills and that with such an improvement students were led to reevaluate their entire conceptual framework. The Concordia students in their interviews confirm this hypothesis. Further confirmation is given by the College student interviews. As such, the combination of the collaborative-group exercises and the critique writing activity has been shown to promote critical examination of alternative possibilities, thus achieving the second main goal of the study.

In summary, altogether these instructional activities were proven to be successful in helping students develop a "scientific mindset." Both the quantitative and qualitative results have demonstrated that students were able to change their outlook on the course material from the fragmented viewpoint that it consists of a tool kit of assorted practices to the 
more holistic and integrated viewpoint that in actuality it comprises a connected structure of concepts. Through this program of research, by creating instructional activities designed to change students' epistemologies and implementing these in the classroom, we have demonstrated significant gains in the understanding of the subject by our students.

\section{ACKNOWLEDGMENTS}

This work supported in part by the following grants: SSHRC (Social Sciences and Humanities Research Council of Canada), FRSQ (Fonds de recherche sur la société et la culture).
[1] W. Cobern, Science education as an exercise in foreign affairs, Sci. Educ. 4, 287 (1995).

[2] D. Hammer, Two approaches to learning physics, Phys. Teach. 27, 664 (1989).

[3] D. Hammer, Epistemological beliefs in introductory physics, Cogn. Instruct. 12, 151 (1994).

[4] D. Hammer and A. Elby, in Personal epistemology: The Psychology of Beliefs About Knowledge and Knowing, edited by B. Hofer and P. R. Pintrich (Erlbaum, Mahwah, 2002), pp. 169-190.

[5] W. A. Sandoval and K. Morrison, High school students' ideas about theories and theory change after a biological inquiry unit, J. Res. Sci. Teach. 40, 369 (2003).

[6] D. Huffman and P. Heller, What does the force concept inventory actually measure? Phys. Teach. 33, 138 (1995).

[7] G. Posner, K. Strike, P. Hewson, and W. Gertzog, Accommodation of a scientific conception: toward a theory of conceptual change, Sci. Educ. 66, 211 (1982).

[8] I. Halloun and D. Hestenes, Common sense concepts about motion, Am. J. Phys. 53, 1056 (1985).

[9] L. McDermott, Research on conceptual understanding in mechanics, Phys. Today 37(7), 24 (1984).

[10] L. McDermott, M. Rosenquist, and E. van Zee, Student difficulties in connecting graphs and physics: Examples from kinematics, Am. J. Phys. 55, 503 (1987).

[11] R. Gunstone, C. Robin Gray, and P. Searle, Some Long-Term Effects of Uninformed Conceptual Change, Sci. Educ. 76, 175 (1992).

[12] J. Bowden, G. Dall'Alba, E. Martin, D. Laurillard, F. Marton, G. Masters et al., Displacement, velocity, and frames of reference: Phenomenographic studies of students' understanding and some implications for teaching and assessment, Am. J. Phys. 60, 262 (1992).

[13] S. Vosniadou, Capturing and modeling the process of conceptual change, Learn. Instr. 4, 45 (1994).

[14] E. Seymour and N. M. Hewitt, Talking About Leaving: Why Undergraduates Leave the Sciences (Westview Press, Boulder, 1997).

[15] D. J. Watters and J. J. Watters, Approaches to learning by students in the biological sciences: implications for teaching, Int. J. Sci. Educ. 29, 19 (2007).

[16] P. K. Feyerabend, Against Method (Verso, New York, 1993).

[17] G. Galilei, Trattato della Sfera Opere (Picciardi, Milano, 1953), Vol. II.

[18] T. S. Kuhn, The Structure of Scientific Revolutions (University of Chicago Press, Chicago, 1970).

[19] P. Hewitt, Lessons from Lily on the introductory course, Phys. Today 48(9), 85 (1995).

[20] C. W. Keys, B. Hand, V. Prain, and S. Collins, Using the science writing heuristic as a tool for learning from laboratory investigations in secondary science, J. Res. Sci. Teach. 36, 1065 (1999).

[21] A. R. McCrindle and C. A. Christenson, The impact of learning journals on metacognitive and cognitive processes and learning performances, Learn. Instr. 5, 167 (1995).

[22] L. Mason and P. Boscolo, Writing and conceptual change: what changes, Instr. Sci. 28, 199 (2000).

[23] C. S. Kalman, Generating effective in-class discussions, The Successful Professor, 1, (2002).

[24] C. S. Kalman, in Colleges And Universities (Jossey-Bass/ Wiley Inc., 2006).

[25] R. Berg, The Video Encyclopedia of Physics Demonstrations (The Education Group, Los Angeles, 1992).

[26] I. Halloun and D. Hestenes, The initial knowledge state of college physics students, Am. J. Phys. 53, 1043 (1985).

[27] P. Hewson and M. Hewson, The role of conceptual conflict in conceptual change and the design of science instruction, Instr. Sci. 13, 1 (1984).

[28] W. M. Roth and K. Lucas, From "Truth" to "Invented Reality:" A Discourse analysis of high school physics students' talk about scientific knowledge, J. Res. Sci. Teach. 34, 145 (1997).

[29] C. S. Kalman, A role for experiment in using the law of inertia to explain the nature of science: a comment on Lopes Celho, Sci. Educ. 18, 25 (2009).

[30] R. J. Sternberg, Thinking styles: Keys to understanding student performance, Phi Delta Kappan 71, 366 (1990).

[31] C. E. Nelson, Critical Thinking and Collaborative Learning, Collaborative Learning: Underlying Processes and Effective Techniques, Higher and Adult Education Series, edited by K. Bosworth and J. Sharon (Jossey-Bass, San Francisco, 1994).

[32] C. S. Kalman, S. Morris, C. Cottin, and R. Gordon, Promoting conceptual change using collaborative groups in quantitative gateway courses, Am. J. Phys. 67, S45 (1999).

[33] C. S. Kalman, S. Rohar, and D. Wells, Enhancing conceptual change using argumentative essays, Am. J. Phys. 72, 715 (2004).

[34] D. Hestenes, M. Wells, and G. Swackhamer, Force concept inventory, Phys. Teach. 30, 141 (1992).

[35] C. S. Kalman, M. W. Aulls, J. Godley, and S. Rohar, Students' perceptions of reflective writing as a tool for exploring an introductory textbook, J. Sci. Coll. Teach. 37, 74 (2008).

[36] R. E. Stake, in Handbook of Qualitative Research in Education, edited by N. K. Denison and Y. S. Lincoln (Prentice Hall, New York, 1998).

[37] S. B. Merriam, Case Study Research in Education: A Qualitative Approach (Jossey-Bass, San Francisco, 1988).

[38] J. N. Moschkovich and M. E. Brenner, Integrating A Naturalistic Paradigm Into Research On Mathematics And Science Cognition And Learning, Handbook of Research Design in 
Mathematics and Science Education, edited by A. E. Kelley and R. A. Lesh (Lawrence Erlbaum, Mahwah, 2000), Chap. 17, pp. 457-486.
[39] E. F. Redish, Teaching Physics: With The Physics Suit (Wiley, New York, 2003). 